DOI: $10.21278 /$ TOF.41205

ISSN 1333-1124

eISSN 1849-1391

\title{
DETERMINING AN ALLOWABLE WEAR OF WORM WHEELS
}

\begin{abstract}
Summary
The paper presents an analysis based on the two criteria used to determine an allowable sliding wear of the worm gear side teeth and of the worm wheels. In both cases, two undesirable consequences occurred. The first one is a reduction in the tooth root cross section, which may lead to tooth fracture. The other one is the appearance of tooth tapers. Both consequences are undesirable in all types of gear transmissions because of the risk of tooth fracture.
\end{abstract}

Key words: $\quad$ worm wheels, tooth fracture, tooth wear, tooth taper, tooth root

\section{Introduction}

In comparison with all other gears, worm gears exhibit relatively high energy losses during operation in spite of their good features. This fact was a starting point for conducting this research. The aforementioned fact defined our research focused on an improvement in durability, cheaper manufacturing, and reduced energy losses. The worm gear durability is determined by a tribological system which includes the worm material, the worm wheel material, and the lubricant. The materials in this tribological system are similar to the materials in journal bearings. The worm screw - journal relation and the worm wheel bearing lining relation, along with a lubricant as the third component, represent the key elements of the total no-load energy loss of a worm gear. Recently, efforts have been made to replace tin bronze with a more suitable bronze type, at least as far as the price is concerned. In this respect, aluminium bronze has been highlighted as particularly suitable. The current scientific research demonstrates a possibility of using aluminium alloys. More details on this topic can be found in the papers written by Niemann [1], Winter [2], Huber [3], Opalić [4, 5], Žeželj [6], and Panić [7].

The third factor in a tribological system is a lubricant, which has an important role both in wear reduction and in increasing the resistance to contact pressure. When synthetic lubricants appeared on the market, it was considered that they contributed to an improved contact pressure limit, but some authors proved the opposite, having compared the synthetic lubricants with the mineral ones, e.g., Huber [3], Wilkesmann [9], Opalić [4, 5], Žeželj [6], Panić [7] and Muminović [8]. 
In real conditions, the main problem is that the viscosity of a lubricant cannot be clearly defined. This issue has to be further clarified with respect to the working temperature and an allowable pressure at a critical point of contact between the worm and the worm wheel.

\section{Calculation}

When a worm gear is lubricated by immersion, there are two ways of determining the allowable wear:

1. wear restriction by protecting the worm wheel tooth root from fracture (i.e. from the critical weakening of the tooth root by the cross section reduction due to wear);

2. wear limitation through the tooth thickness at the worm wheel crown diameter (i.e. the undesirable pointedness of the tooth is avoided by a tip tooth thickness of $\left.\mathrm{s}_{\mathrm{a}}>0\right)$.

In order to determine the allowable wear of the first possibility (i.e. a minimum cross section of the tooth root), the following calculation according to Niemann will be applied [2]:

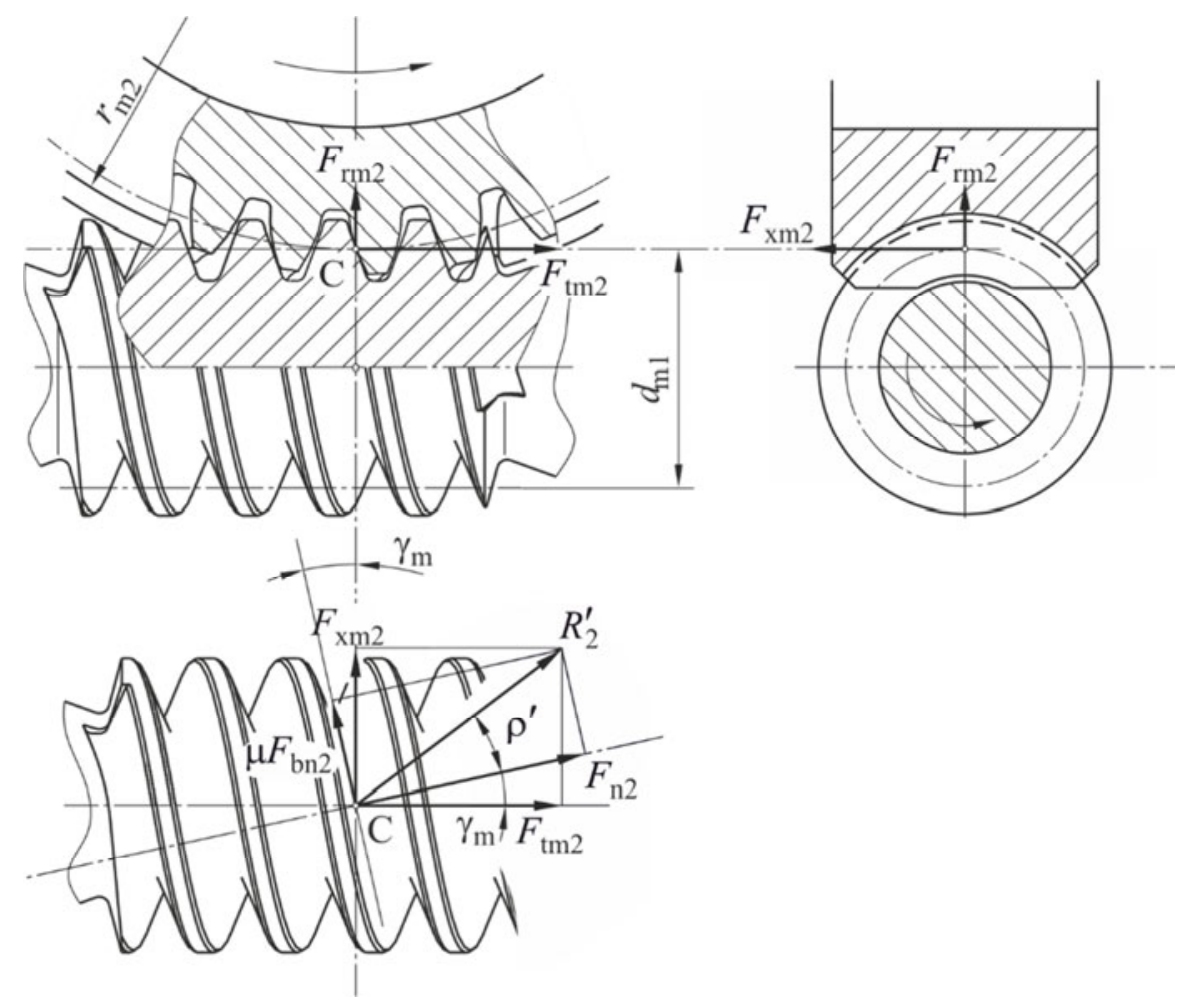

Fig. 1 Tooth load

$$
\begin{aligned}
F_{\mathrm{tm} 2} & =\frac{p_{\mathrm{x}} \cos \gamma_{\mathrm{m}} b_{2} \tau_{\mathrm{F} \lim \mathrm{T}}}{S_{\mathrm{F}}}=\frac{m_{\mathrm{n}} \pi \cos \gamma_{\mathrm{m}} b_{2} \tau_{\mathrm{F} \operatorname{lim~T}}}{S_{\mathrm{F}}}= \\
& =\frac{2 s^{\prime \prime} \cos \gamma_{\mathrm{m}} b_{2} \tau_{\mathrm{F} \lim \mathrm{T}}}{S_{\mathrm{F}}}
\end{aligned}
$$

Where

$F_{\mathrm{tm} 2}, \mathrm{~N}-$ the circumferential or tangential force on the worm wheel,

$p_{\mathrm{x}}, \mathrm{mm}-$ the axial pitch of the worm,

$\gamma_{\mathrm{m}},{ }^{\circ}-$ the reference lead angle of the worm, 
$b_{2}, \mathrm{~mm}$ - the facewidth of the wheel,

$\tau_{\mathrm{F} \lim \mathrm{T}}, \mathrm{N} / \mathrm{mm}^{2}-$ the shear endurance strength,

$S_{\mathrm{F}},--$ the tooth breakage safety factor,

$m_{\mathrm{n}}, \mathrm{mm}-$ the normal module,

$s, \mathrm{~mm}-$ the initial tooth thickness,

$s^{\prime \prime}, \mathrm{mm}-$ the tooth thickness after a certain period of time.
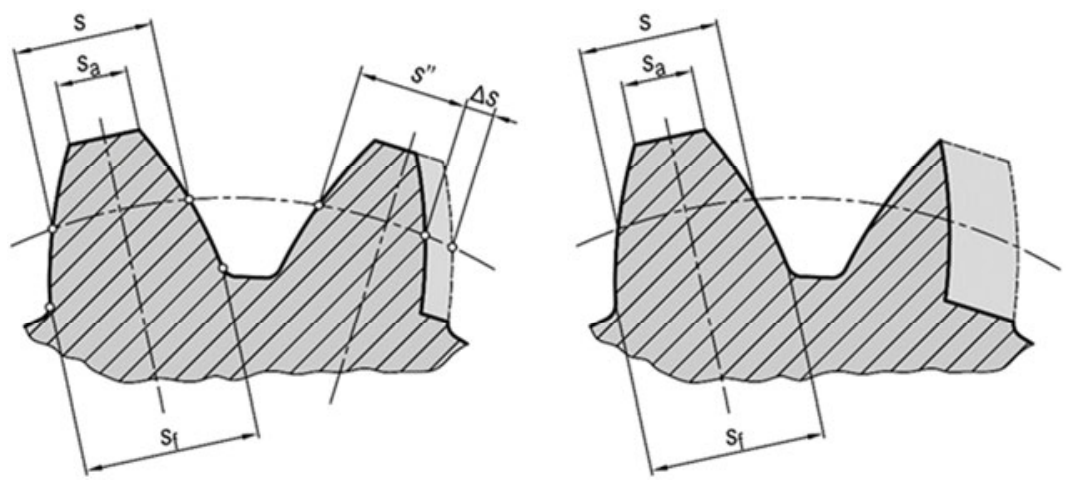

Fig. 2 A simplified image of a decrease in the tooth thickness due to an increased wear (cross-section)

During the worm gear service life, the tooth thickness $s$ will be reduced to the size $s^{\prime \prime}$ (Figure 2), so after a certain period of time, the tooth thickness can be expressed as follows:

$$
s^{\prime \prime}=s-\Delta s
$$

By introducing the output torsion moment $T_{2}$, the following expression will be obtained:

$$
T_{2 \max }=\frac{(s-\Delta s) d_{\mathrm{m} 2} \cos \gamma_{\mathrm{m}} b_{2} c_{\mathrm{gr}}}{S_{\mathrm{F}}}
$$

leading to

$$
\Delta s=\frac{m \pi}{2}-\frac{T_{2 \max } S_{\mathrm{F}}}{d_{\mathrm{m} 2} \cos \gamma_{\mathrm{m}} b_{2} c_{\mathrm{gr}}}
$$

After inserting the parameters of the tested gear in Equation (4), the values of allowable wear $\Delta s_{\text {lim }}$ are calculated as the root strength criterion for different output torques and the root resistance to fracture for the material AlSn6.

Table 1 The calculated values of an allowable tooth root thickness reduction as the root strength criterion

\begin{tabular}{|c|c|c|}
\hline$T_{2}, \mathrm{~N} \cdot \mathrm{m}$ & \multicolumn{2}{|c|}{$\Delta s_{\text {lim }}, \mathrm{mm}$} \\
\hline & $S_{\mathrm{F}}=1$ & $S_{\mathrm{F}}=1.2$ \\
\hline 180 & 3.852 & 3.367 \\
\hline 210 & 3.447 & 2.881 \\
\hline 260 & 2.772 & 2.071 \\
\hline 310 & 2.096 & 1.261 \\
\hline 370 & 1.286 & 0.289 \\
\hline
\end{tabular}


Based on Table 1, the relationship between an allowable tooth change and a specific wear can be obtained by calculating the volume loss due to wear and by multiplying it by the specific weight of the wheel tooth material.

The surface area of one worm gear tooth (i.e. the surface area of a projected wheel side) can be approximately calculated by the following expression (Figure 3 ):

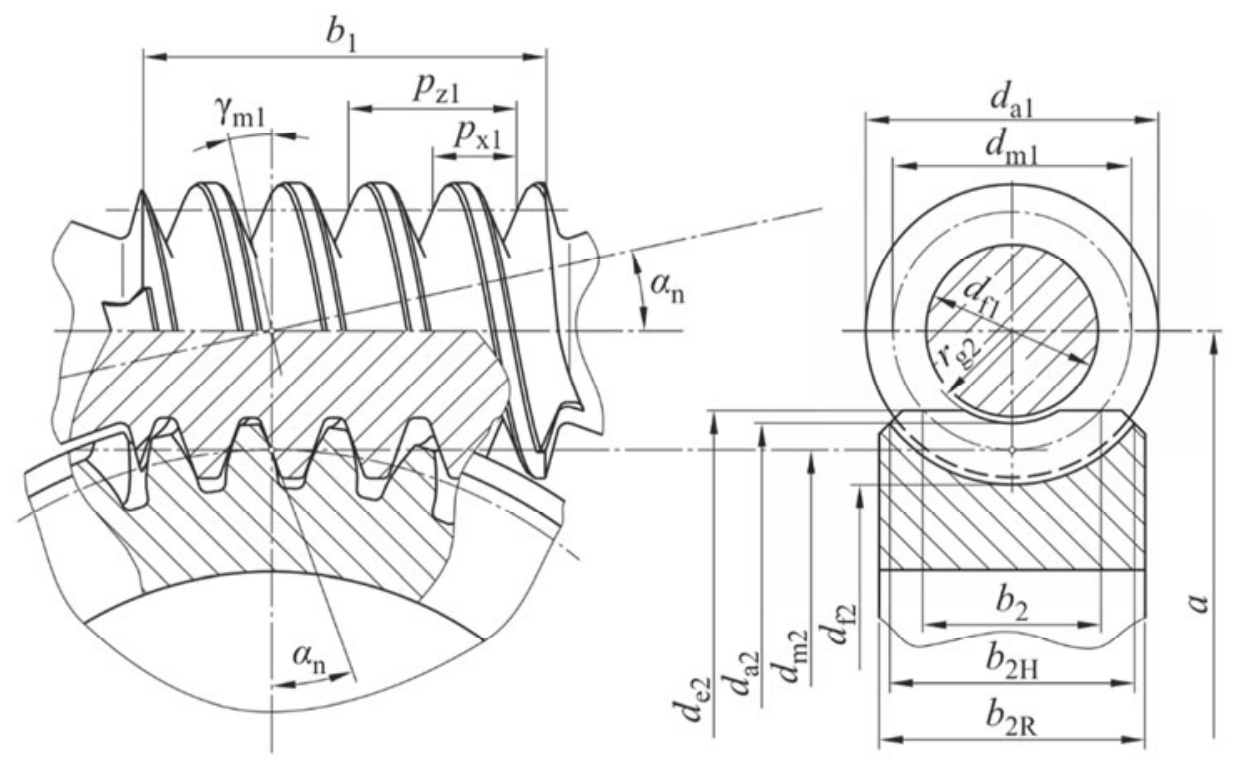

Fig. 3 The parameters for the tooth surface area calculation

$$
A_{\mathrm{z} 21}=\frac{d_{1} \pi m \arcsin \left(\frac{b_{2}}{d_{1}+2 m}\right)}{90 \cos \gamma_{\mathrm{m}} \cos \alpha_{\mathrm{n}}}
$$

After inserting the values of the tested gear into Equation (5), the surface area of a single wheel tooth is obtained:

$$
A_{\mathrm{z} 21}=213 \mathrm{~mm}^{2}
$$

The calculated surface area is smaller than the actual one because of the tooth curvature [5]. By numerical integration we get an area of $256.8 \mathrm{~mm}^{2}$ while by measuring a 3D CAD model, the area of $258.6 \mathrm{~mm}^{2}[6,7]$.

The total surface of wheel teeth amounted to:

$$
A_{2 \mathrm{uk}}=z \quad A_{\mathrm{z} 213 D}=9,309.6 \mathrm{~mm}^{2}
$$

The value of allowable specific sliding wear is obtained on the basis of a specific weight of $2.84 \mathrm{~g} / \mathrm{cm}^{3}$ of the tested alloy and a service life of 12,000 hours, as well as on the basis of the tooth root strength criterion. The calculation results are presented in Table 2.

Table 2 The calculation results of allowable specific sliding wear as the tooth root strength criterion. (The values refer to a service life of 12,000 hours.)

\begin{tabular}{|c|l|r|}
\hline$T_{2}(\mathrm{~N} \cdot \mathrm{m})$ & \multicolumn{2}{|c|}{$\Delta m s_{\text {lim }}, \mathrm{mg} / \mathrm{h}$} \\
\hline & $S_{\mathrm{F}}=1$ & $S_{\mathrm{F}}=1.2$ \\
\hline 180 & 8.487 & 7.418 \\
\hline
\end{tabular}




\begin{tabular}{|c|c|c|}
\hline$T_{2}(\mathrm{~N} \cdot \mathrm{m})$ & \multicolumn{2}{|c|}{$\Delta m s_{\text {lim }}, \mathrm{mg} / \mathrm{h}$} \\
\hline 210 & 7.595 & 6.348 \\
\hline 260 & 6.107 & 4.563 \\
\hline 310 & 4.618 & 2.778 \\
\hline 370 & 2.833 & 0.637 \\
\hline
\end{tabular}
follows:

Referring to a different service life, the values presented in Table 2 will be calculated as

$$
\Delta m s_{\operatorname{limxh}}=\frac{\Delta m s_{\lim } 12,000}{L_{\mathrm{h}}}
$$

where

$\Delta m s_{\text {limxh }}, \mathrm{mg} / \mathrm{h}$-the allowable specific wear for the desired service life,

$\Delta m s_{\text {lim }}, \mathrm{mg} / \mathrm{h}-$ values in Table 2 ,

$L_{\mathrm{h}}, \mathrm{h}-$ the desired service life.

Based on the calculated values of the allowable wear in accordance with the two criteria (i.e. the tooth root strength and the tooth taper), Figure 4 shows the allowable output torques correlated to the main shaft speed:

AlSn6/34CrMo4 mineral oil, $T_{\mathrm{u}}=60^{\circ} \mathrm{C}$.

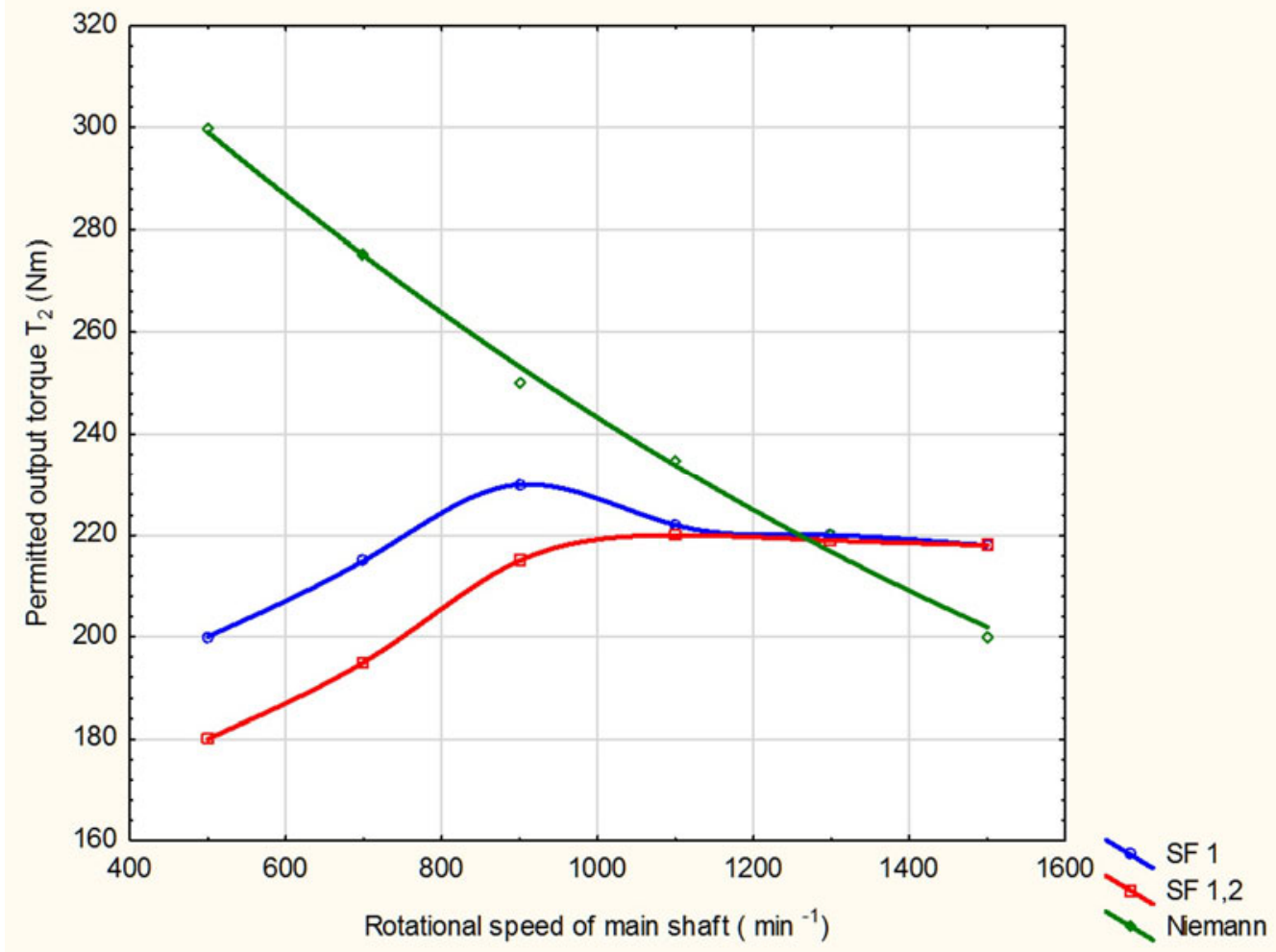

Fig. 4 The allowable output torques of the tested gear according to the tooth taper and tooth root strength criteria $[1,5,7] . \mathrm{S}_{\mathrm{F}}$ is the tooth breakage safety factor 


\section{Conclusion}

The obtained results show that there is a relatively simple method for determining the allowable wear of the worm gear and the worm wheel teeth. Depending on the worm wheel material, it is possible to satisfy one of the criteria (e.g. the tooth taper or the tooth root strength) before satisfying the other. This paper presents the calculations for $s_{\mathrm{a}}=0$ (i.e. the theoretical taper limit), while in practice, the calculations will be performed with a minimum $s_{\text {amin }}$ of $0.4 m$.

\section{REFERENCES:}

[1] Niemann, G., Weber, C., Schneckentriebe mit flüssiger Reibung, VDI-Forschungsheft 412, 1942.

[2] Niemann, G., Winter, H., Maschinenelemente, Band III, 2. Auflage, Springer Verlag Berlin, Heidelberg, New York, Tokyo, 1986.

[3] Huber, G., Untersuchungen über Flankentragfähigkeit und Wirkungsgrad von Zylinderschneckengetrieben (Evolventenschnecken), Dissertation, TH-München, 1978.

[4] M. Opalić, Contribution to the study of load capacity of worm wheels, Faculty of Mechanical Engineering and Naval Architecture, (1984). Doctoral thesis. (Croatian).

[5] Opalić, M., Material impact on the carrying capacity research of worm gears, Strojarstvo 23 (1981), 4, 177-181. (Croatian).

[6] Žeželj, D., Load carrying capacity research of worm gears, Faculty of Mechanical Engineering and Naval Architecture, (2007). Doctoral thesis. (Croatian).

[7] Panić, N., Wear of worm wheels tooth face, Faculty of Mechanical Engineering and Naval Architecture, (2013). Doctoral thesis. (Croatian).

[8] Muminović, A., Repčić, N., Žeželj, D. The efficiency of worm gears lubricated with oils of mineral and synthetic bases. Transactions of FAMENA, 37 (2013), 4, 65-72

[9] Wilkesmann, H., Berechnung von Schneckentrieben mit unterschiedlichen Zahnprofilformen, Dissertation, TU München, 1974.

Submitted: $\quad 19.9 .2016$

Accepted: $\quad 02.3 .2017$
Nenad Panić

Faculty of Mechanical Engineering and Naval Architecture, HR-10002 Zagreb, Ivana Lučića 5

Branko Katana

University of Applied Sciences Velika Gorica, HR-10410 Velika Gorica, Zagrebačka 5

Zvonimir Ivan Mrčela

Faculty of Electrical Engineering,

Computer Science and Information

Technology Osijek, HR-31000 Osijek, Kneza Trpimira 2B 